\title{
An extra pair of hands? Evaluation of salaried payment for general practitioners
}

Anthony Scott Health Economics Research Unit, University of Aberdeen, Scotland, UK, Frank Sullivan Research and Development in Primary Care, Tayside Centre for General Practice, University of Dundee, Scotland, UK, Sarah Wordsworth Health Economics Research Centre, University of Oxford, Headington, UK and David Heaney Highlands and Islands Health Research Institute, University of Aberdeen, Scotland, UK

The aim of this article is to report the results of a study examining salaried payment for general practitioners (GPs) in Scotland. The study examines 'paragraph 52' salaried payment, where GPs can employ a GP as a member of practice staff and claim reimbursement from the health board. The paper reports results of 18 semi-structured interviews with managers at two health boards, and at seven general practices who have a salaried GP.The paper also presents quantitative data about the nature of the salaried contracts and presents a comparison of practices with a salaried GP with other practices in Scotland. Seventeen practices employed a salaried GP 18 months after the scheme began. Ex-fundholders and training practices were more likely to have been selected by health boards to employ a salaried GP. The two health boards took different approaches to the scheme. The first selected those practices that were more likely to have identified specific service developments as part of their bid for a salaried GP. This approach might reward those practices that were already innovative, thus potentially increasing inequality in service provision between practices. The second health board used the scheme to maintain and support practices in rural areas, and was less concerned with service development, thus potentially reducing inequalities in access. Salaried GPs were ex-GP registrars and ex-locums who wanted more stability and less responsibility, and administration. Some were happy in their post, while others saw it as a stepping stone to a partnership. Most practices used the salaried GP to release the time of partners to engage in practice development. Some practices mentioned the financial benefits of the scheme and benefits in terms of enabling service development. Compared to using locums, it was suggested that referral rates of salaried GPs may be lower, and continuity of care higher. Participants felt strongly that the scheme should continue. The paragraph 52 scheme was used little, but was potentially valuable in introducing stability and experience for younger GPs who do not want a partnership. Health boards had different interpretations of the objectives and use of the scheme reflecting different local circumstances. The potential of the scheme to address inequalities in the distribution of GPs is uncertain.

Key words: family physicians; job satisfaction; physician incentive plans; reimbursement mechanisms; workforce

Received: April 2003; accepted: August 2005

Address for correspondence: Professor Anthony Scott PhD, Melbourne Institute of Applied Economic and Social Research, The University of Melbourne, Parkville, VIC 3010, Australia. Email: a.scott@unimelb.edu.au

\section{Introduction}

A salaried option for general practitioners (GPs) in the National Health Service (NHS) in the UK was 
introduced under two separate pieces of legislation. The first was the 1997 Primary Care Act, which allowed GPs to opt out of the national GP Contract and be employed directly by the General Practice or Hospital Trust, or the whole practice could contract directly with the health authority or health board to provide Personal Medical Services (PMS). The second piece of legislation made an amendment to paragraph 52 of the Statement of Fees and Allowances that allowed practices to employ GPs as practice staff, with reimbursement from the health board from General Medical Service (GMS) cash limited funds. This scheme began in England and Scotland in April 1998.

Although there is evidence to suggest that remuneration systems can influence clinical behaviour, there is little evidence about their effect on recruitment and retention or inequalities in the distribution of GPs (Gosden et al., 1999; 2000; Scott, 2000). The national evaluation of PMS Pilots found that salaried GPs were equally as satisfied overall with their job as standard contract GPs, although salaried GPs were more satisfied with remuneration, working hours and recognition for good work. Salaried GPs were also less stressed (Gosden et al., 2002). A further finding was that recruitment success was similar to that achieved by inner city practices (Williams et al.,2001). The main benefits of salaried posts were perceived to be reduced out of hours work and freedom from administrative responsibilities.

The aim of this paper is to examine how the paragraph 52 salaried GP scheme was being implemented in Scotland. The study includes a quantitative comparison of practices with and without a salaried GP, and also reports results from semistructured interviews with health board managers, lead GPs, and salaried GPs.

Details of the scheme were set out in NHS Circular PCA(M) (1998). This specified a variety of reasons why a practice might want to apply. The scheme provides for payment, at the health board's discretion, of all or part of the expense of a GP principal employing a salaried doctor. An uplift of $£ 6 \mathrm{~m}$ in cash limited funding for 1997/98 and for 1998/99 was made available for this and other primary care initiatives. Proposals and criteria for assessing them were to be determined annually by the Health Board and Area Medical Committee. Each health board therefore had limited funds for the scheme, and had discretion as to whether funds were used for the salaried scheme or other primary care developments.

\section{Methods}

The analysis in this paper is based on a conceptual framework that views funding changes and resultant financial incentives as a communication process (Giacomini and Goldsmith, 1996; Giacomini et al., 1996). This framework emphasises the social and institutional context of the funding change, and views funding changes as carrying messages that are open to interpretation. This can influence the effectiveness of the funding change in meeting its intended objectives. For this project, the framework emphasises the need to compare the perceptions of those implementing the funding change (ie, health boards) and those who are targets of the funding change (ie, general practices), and the need to identify any unintended behavioural consequences of the funding change.

Quantitative and qualitative methods were used. A combination of methods serve to strengthen the conclusions from individual methods, as they should reveal similar types of information gathered using completely different types of data. Both methods were used to explore the characteristics of salaried GP practices and to examine potential reasons why some practices had a salaried GP and others did not. Each method is likely to reveal different, but complimentary reasons that explain the differential response of GPs and health boards to the scheme.

All 15 health boards in Scotland were contacted to obtain the details of every practice which employed a salaried GP, and to obtain any documentation, such as bids and contracts. Descriptive information about each of these practices, and all other practices in Scotland were also obtained from the Information and Statistics Division of the Scottish Executive, and used to compare practices with and without a paragraph 52 salaried GP.

The qualitative part of the study involved conducting semi-structured interviews with key stakeholders. The study was conducted in two of the three health boards with salaried GPs, reflecting the sources of funding for this study. All salaried practices in each of the two health boards were approached to be involved in the study. Seven case studies were undertaken, each one comprising a 
general practice that employed a salaried GP. For each case study, we conducted separate semi-structured interviews with a representative of the health board, the lead GP in the practice and the salaried GP employed by the practice.

The interview schedules asked about perceptions of the history and set up of the scheme; perceptions of the objectives, advantages and disadvantages of the scheme; issues about the level of payment and nature of the contract (including process of negotiation, working patterns, and likely effects on patients); and the future of the scheme.

\section{Data analysis}

Quantitative data comparing practice characteristics were analysed in SPSS. Interviews were conducted by two interviewers, were audio-taped and then transcribed verbatim. Transcriptions were read and summarized independently by two of the authors (AS and SW). They then met to resolve any differences of interpretation or emphasis. Summaries were produced by classifying phrases and sentences into each of four headings (history and set up; objectives, advantages, and disadvantages; level of payment and nature of the contract; and future of the scheme). These were organized into matrices to aid visual comparison of text within and across each case study (Pope et al., 2000).

\section{Results}

Eighteen months after the introduction of the scheme, 17 practices in three mainland health boards employed a salaried GP. Three practices in another mainland health board were about to employ a salaried GP, another health board had previously used the scheme to fill short-term gaps in provision, and practices in one island health board were about to employ four salaried GPs.

Table 1 represents a comparison of practices with a paragraph 52 salaried GP to those practices with no paragraph 52 GP. There were few statistically significant differences. Practices with salaried GPs have a larger list size, but similar numbers of partners and workload (list size per GP). Practices with salaried GPs are more likely to have been fundholders and be a training practice, although other indicators of innovation were similar. There were few differences related to geographical or patient characteristics.

Eighteen interviews were conducted over a period of six months. Interviews were conducted with the particular manager responsible for the scheme in each of the two health boards. In health board 1, there were seven practices with a salaried GP. Separate interviews with both the lead GP and salaried GP were completed in six practices (for one practice, the quality of tape-recording was too poor and interviews could not be transcribed). In health board 2, there were two practices with a salaried GP, and one set of interviews with both the lead GP and salaried GP were conducted. Interviews with the lead GP and salaried GP were conducted on the same day if possible.

\section{Objectives, advantages, and disadvantages}

In the first health board, most practices chosen were ex-fundholders in urban areas, which were not explicit criteria for selection. The health board manager wanted to see the scheme used for service development and research, but also for GPs to gain experience between training and a partnership. The same manager stated that he did not want practices applying for a 'cheap pair of hands', 'in other words a practice, instead of taking on another partner or being over worked, they'd get a salaried partner'. All GP principals stated that there were problems in developing the practice's services due to lack of time. One practice applied to ensure access to a female partner. Some had tried to apply for associates or were on the retainer scheme. Most mentioned that they would experience a drop in income if another partner was employed, and some mentioned the additional costs of employing locums to enable partners to develop the practice. It seemed most considered the financial benefits of the salaried scheme, but also mentioned the use of the salaried GP to develop patient services. It is difficult to find out which objective dominated their decision (ie, income or benefits to patients from practice developments). This raises doubts as to whether the intentions of the health board were realised, in terms of not letting practices have a 'cheap pair of hands'. It was also suggested (by some principals and salaried GPs) that practices with salaried GPs would have lower referral rates than practices who used locums, although a new salaried GP might 
Table 1 Comparison of practice characteristics (salaried GPs in post at September 1999)

\begin{tabular}{|c|c|c|c|}
\hline & $\begin{array}{l}\text { Practices with a } \\
\text { salaried GP } \\
(n=17)\end{array}$ & $\begin{array}{l}\text { Practices without a } \\
\text { salaried GP } \\
(n=1054)\end{array}$ & $P$-value \\
\hline \multicolumn{4}{|l|}{ Practice size } \\
\hline List size (median) & 7300 & 4495 & $0.08^{b}$ \\
\hline Number of partners (median) & 5 & 3 & $0.13^{b}$ \\
\hline $\begin{array}{l}\text { Number of whole time equivalent } \\
\text { (WTE) partners (median) }\end{array}$ & 5 & 3 & $0.10^{\mathrm{b}}$ \\
\hline List size per WTE GP & 1613 & 1497 & $0.25^{\mathrm{c}}$ \\
\hline Total GMS income per WTE GP & £63396 & £61 790 & $0.39^{c}$ \\
\hline \multicolumn{4}{|l|}{ Factors related to innovation } \\
\hline Previously a fundholding practice (\%) & 71 & 48 & $0.07^{a}$ \\
\hline Practice received an improvement grant (\%) & 24 & 16 & $0.37^{\mathrm{a}}$ \\
\hline Training practice $(\%)$ & 53 & 26 & $0.01^{\mathrm{a}}$ \\
\hline $\begin{array}{l}\text { Income from practice staff salaries } \\
\text { per } 1000 \text { population (median) }\end{array}$ & £11 274 & f11 253 & $0.68^{b}$ \\
\hline $\begin{array}{l}\text { Number of claims for minor surgery } \\
\text { per } 1000 \text { population (median) }\end{array}$ & 7.18 & 6.84 & $0.14^{b}$ \\
\hline $\begin{array}{l}\text { Percentage of eligible population } \\
\text { receiving a smear test (median) }\end{array}$ & 0.82 & 0.79 & $0.14^{b}$ \\
\hline $\begin{array}{l}\text { Number of night visit claims } \\
\text { per } 1000 \text { population (median) }\end{array}$ & 33 & 34 & $0.09^{b}$ \\
\hline $\begin{array}{l}\text { Number of pre-school boosters } \\
\text { per eligible patient (median) }\end{array}$ & 0.94 & 0.94 & $0.60^{\mathrm{b}}$ \\
\hline $\begin{array}{l}\text { Number of primary childhood immuni- } \\
\text { sations per eligible patient (median) }\end{array}$ & 3.8 & 3.82 & $0.79^{\mathrm{b}}$ \\
\hline \multicolumn{4}{|l|}{$\begin{array}{l}\text { Factors related to geography and } \\
\text { patient characteristics }\end{array}$} \\
\hline $\begin{array}{l}\text { Practices receiving rural practice } \\
\text { payments }(\%)\end{array}$ & 47 & 44 & $0.76^{\mathrm{a}}$ \\
\hline $\begin{array}{l}\text { Rural practice payments per } \\
1000 \text { population (mean) }\end{array}$ & $£ 1390$ & $£ 2129$ & $0.92^{\mathrm{b}}$ \\
\hline $\begin{array}{l}\text { Over } 75 \text { capitation payments as } \\
\text { percentage of total capitation payments } \\
\text { (mean) }\end{array}$ & 0.17 & 0.16 & $0.09^{c}$ \\
\hline $\begin{array}{l}\text { Income for high deprivation patients } \\
\text { per } 1000 \text { population (median) }\end{array}$ & £96 & $£ 54$ & $0.89^{b}$ \\
\hline
\end{tabular}

${ }^{a}$ Pearson chi-squared test; ${ }^{b}$ Mann-Whitney non-parametric test; ${ }^{c}$ independent samples $t$-test

have an initially high referral rate until they get to know patients. We have no quantitative data to examine this issue.

The second health board used the scheme specifically to help practices in rural areas where out of hours cover was a problem. They were less concerned about developing services. Large practices did not express an interest in the scheme and none of those who applied were ex-fundholders. Across both health boards, some practices advertised the post while others already had a GP in mind (usually an ex-trainee or locum).

Salaried GPs were either ex-GP registrars or ex-locums who had already been working at the practice. A minority of practices advertised the post. From the perspective of the salaried GPs, advantages included less administration, management, insurance forms and medicals. Stability of location and some security in terms of salary were also cited. Most salaried GPs mentioned continuity of care as patients return to see them and no out of hours work. Salaried GPs were involved in practice meetings and decisions, and were treated as if they were a partner. Two GPs were unhappy with the level of salary for doing the same work as other GPs. One of these GPs also felt like an 'employee' and did not feel that they 'belonged'. However, others seemed willing to trade-off income for less 
responsibility in terms of practice management decisions and administration. Some were happy with the post, and other regarded it as a 'stepping stone' to a partnership.

Benefits to patients mentioned by GP principals included increased continuity of care for patients (compared to using locums). This would also benefit the salaried GP who could build up their own caseload. In most practices, advantages mentioned by GP principals included the use of the salaried GP to free the time of other partners to pursue practice development and other interests outside the practice. Practice developments included reorganisation of appointments systems, case finding/audit, and more clinics. 'Other' interests that partners were able to pursue included management and external commitments (eg, involvement in local healthcare cooperatives (LHCC)). Some disadvantages included the inability to make longterm plans due to relatively short contracts, low remuneration, and the practices having to pay $15 \%$ of the costs of the post.

\section{Nature of the contracts}

In both health boards, salary level, and reimbursement were decided jointly by the health board and the GP sub-committee. In one health board, salary was set at the level of a 4th year associate GP (£31450), with the health board reimbursing 85\% of costs to encourage practices to make a commitment. One practice increased this using its own funds. Although contract lengths varied (1-5 years), practices had to re-apply annually for funding. In the other health board, $100 \%$ of salary was reimbursed, although the health board manager thought that the level of salary was based on target remuneration, while the GP principal thought it was based on British Medical Association (BMA) locum rates. Contracts varied from part time to full time, some included protected professional development time, and all were for salaried GPs to undertake basic 'GMS' work (ie, 'doing ordinary GPs' work'). Some included requirements to help develop services for specific populations (eg, students, cardiovascular audit, women's health clinic, baby clinic and family planning). Salaried GPs were being used to cover sessions for other partners to free their time. None did out of hours work or management. Some contracts included home visits and on call. One practice did not have maternity cover in the contract and the salaried GP had to leave.

\section{Future of the scheme}

All interviewed would like to see the scheme continue. Some principals predicted a cut back of services if the scheme came to an end, with one principal claiming that it would be, 'back to crisis management'. One of the older GP principals said he would leave and 'sell up' if the scheme ended. Most seemed to prefer a salaried post to locum work.

\section{Discussion}

This study has used both quantitative and qualitative research to investigate the operation of the paragraph 52 salaried payment scheme for GPs in Scotland. The application of the framework of Giacomini et al. (1996) proved useful in terms of structuring the research approach and interviews. This framework is useful when evaluating changes in funding and service provision when a randomised trial or controlled study is not possible, or when it is necessary to find out why a funding change did or did not work.

The results of the quantitative analysis suggested that practices with a salaried GP were more likely to be ex-fundholders and training practices. This may reflect better organization or more experience when putting together bids for extra funding. However, there were few other statistically significant differences, suggesting that, to date, practices with a salaried GP have been set up for a variety of purposes unrelated to measurable practice characteristics. This broadly confirms what was intended by the policy, where the salaried scheme was designed for a range of different reasons.

The interviews from one health board also suggested that most of these practices were in urban areas, while the other health board used the scheme specifically to support practices in rural areas. Although these were not explicit criteria, the findings suggest that it was those practices that were already well organized (or at least successful at bidding for extra money) that were allowed to have a salaried GP. Previous research has found that practices that innovate are more likely to be in affluent areas and areas of population growth, 
that is, areas with perhaps the least 'need' for innovation (Bosanquet and Leese, 1988). This may serve to increase inequality in service provision between general practices. This is supported by the quantitative data suggesting that former fundholders and training practices were more likely to have a salaried GP, suggesting again that the strategy of 'rewarding' already innovative practices may have predominated at a national level, potentially increasing inequalities in the distribution of GPs.

The health board that specifically used the scheme to support rural practices seemed to have already identified practices most 'in need' in terms of gaps in provision in rural areas, thus potentially reducing inequality in access. The two health boards therefore used the scheme very differently. The degree of flexibility of the policy meant that health boards (and GP sub-committees) did have discretion in how the scheme operated.

Most of the information obtained from the interviews was descriptive, and there were few differences or anomalies within practices, that is, GP principals and salaried GPs provided similar and complementary information.

Although one health board manager did not want the scheme to be used as a 'cheap pair of hands', it was difficult to unravel GP principals' motivations for wanting a salaried GP. Most mentioned issues suggesting that the salaried GP was a 'cheap pair of hands', in that it saved them money compared to other alternatives (eg, a new partner and locums) but they also mentioned the opportunity the scheme provided to free partners time to develop and the practice. Salaried GPs also felt as if they were treated as partners and were involved in practice decisions, suggesting their work and views were respected by partners.

The role of continuity of care was also mentioned frequently as the mechanism by which patient satisfaction and health outcomes could be affected, at least compared to the use of locum GPs where there is less continuity of care. A practice that regularly uses locums may also have higher referral (and prescribing) rates than a practice with a salaried GP.

Our study also demonstrated the use of the 'communication' framework of Giacomini et al. (1996) for analysing the effects of funding changes. This was useful in structuring the qualitative component of the study. An extension to the study could involve interviewing those who formulated the policy, and those practices whose applications were turned down. The use of the framework gives a more detailed perspective on how financial incentives are constructed by the perceptions of affected organizations. Compared to a locum GP, the funding change could potentially influence referral rates and continuity of care - these effects were not objectives of the funding change, although indicate the likely effects of the scheme on quality of care and costs. As is the case with paragraph 52 salaried payment, this may be important when the objectives of the policy change are vague, or the policy suggests many different uses for the funding change. Examining some of the (unintended) behavioural consequences of the funding change is therefore important. This framework is a useful adjunct to the more usual quantitative type of economic analysis, and may help explain why 'incentives' work for some and not for others, or in one context rather than another.

Given that the scheme was voluntary, and that the funds made available could also be used for many other types of service development, it is perhaps not surprising that only three health boards were using the scheme 18 months after its introduction. Each health board had many more applications than it could fund, suggesting that demand for the scheme was high. However, national guidelines for the scheme were vague and funding short-term. For the scheme to be adopted more widely, both guidance and funding would need to be addressed.

\section{Acknowledgements}

Thanks go to Gareth Jones for conducting some of the interviews, and to John Cairns for comments. This study was funded by two Health Boards, via Tayside Centre for General Practice. The Health Economics Research Unit is funded by the Chief Scientist Office of the Scottish Executive Health Department. The views in this paper are those of the authors and not the funders.

\section{References}

Bosanquet, N. and Leese, B. 1988: Family doctors and innovation in general practice. British Medical Journal 296: 1576-80.

Giacomini, M., Hurley, J., Lomas, J., Bhatia, V. and Goldsmith, L. 1996: The many meanings of money: a health policy 
analysis framework for understanding financial incentives in context. McMaster University Centre for Health Economics and Policy Analysis Working Paper 96-6.

Giacomini, M. and Goldsmith, L. 1996: Case study methodology for studying financial incentives in context. McMaster University Centre for Health Economics and Policy Analysis Working Paper 96-15.

Gosden, T., Pedersen L. and Torgerson, D. 1999: How should we pay doctors? A systematic review of salaried payments and their effects on doctor behaviour. Quarterly Journal of Medicine 92: 47-55.

Gosden, T., Forland, F., Kristiansen, I.S., Sutton, M., Leese, B., Giuffrida, A., Sergison, M. and Pedersen, L. 2000a: Capitation, salary, fee-for-service and mixed systems of payment: effects on the behaviour of primary care physicians
[Systematic Review]. Cochrane Effective Practice and Organisation of Care Group, Cochrane Database of Systematic Reviews.

Gosden, T., Leese, B., Petchey, R., Williams, J. and Sibbald, B. 2002: Salaried contracts in UK general practice: a study of job satisfaction and stress. Journal of Health Services Research and Policy 7, 26-33.

Pope, C., Ziebland, S. and Mays, N. 2000: Analysing qualitative data. British Medical Journal 320: 114-26.

Scott, A. 2000: Economics of general practice. In Newhouse J.P., and Culyer A.J., editors. Handbook of health economics. Amsterdam, North Holland, 1175-94.

Williams, J., Petchey, R., Gosden, T., Leese, B. and Sibbald, B. 2001: A profile of PMS salaried GP contracts and their impact on recruitment. Family Practice 18: 283-87. 